Article

\title{
Further Investigation on Damage Model of Eco-Friendly Basalt Fiber Modified Asphalt Mixture under Freeze-Thaw Cycles
}

\author{
Wensheng Wang, Yongchun Cheng, Guirong Ma, Guojin Tan * ${ }^{\mathbb{D}}$, Xun Sun and Shuting Yang \\ College of Transportation, Jilin University, Changchun 130025, China; wangws17@mails.jlu.edu.cn (W.W.); \\ chengyc@jlu.edu.cn (Y.C.); magrjlu@163.com (G.M.); sunxunjlu@163.com (X.S.); yangstjlu@163.com (S.Y.) \\ * Correspondence: tgj@jlu.edu.cn; Tel.: +86-0431-8509-5446
}

Received: 21 November 2018; Accepted: 21 December 2018; Published: 25 December 2018

\begin{abstract}
The main distresses of asphalt pavements in seasonally frozen regions are due to the effects of water action, freeze-thaw cycles, and so on. Basalt fiber, as an eco-friendly mineral fiber with high mechanical performance, has been adopted to reinforce asphalt mixture in order to improve its mechanical properties. This study investigated the freeze-thaw damage characteristics of asphalt mixtures reinforced with eco-friendly basalt fiber by volume and mechanical properties-air voids, splitting tensile strength, and indirect tensile stiffness modulus tests. Test results indicated that asphalt mixtures reinforced with eco-friendly basalt fiber had better mechanical properties (i.e., splitting tensile strength and indirect tensile stiffness modulus) before and after freeze-thaw cycles. Furthermore, this study developed logistic damage models of asphalt mixtures in terms of the damage characteristics, and found that adding basalt fiber could significantly reduce the damage degree by about $25 \%$, and slow down the damage grow rate by about $45 \%$ compared with control group without basalt fiber. Moreover, multi-variable grey models $(\mathrm{GM})(1, \mathrm{~N})$ were established for modelling the damage characteristics of asphalt mixtures under the effect of freeze-thaw cycles. GM $(1,3)$ was proven as an effective prediction model to perform better in prediction accuracy compared to GM $(1,2)$.
\end{abstract}

Keywords: asphalt mixture; basalt fiber; freeze-thaw cycle; logistic damage model; grey model

\section{Introduction}

Asphalt pavement has been widely used in flexible pavement constructions in a rapidly growing trend [1-4]. Asphalt mixtures are generally considered complex porous materials including asphalt, aggregates, and filler, as well as voids [5-7]. However, due to some environmental factors, there are many distresses in asphalt pavements such as spalling, crumbling, pavement potholes, etc., especially in seasonally frozen regions [8-10]. Therefore, researchers have been trying to modify asphalt mixture and explore its freeze-thaw damage.

Experiments about freeze-thaw cycle effects on asphalt mixtures have been investigated by many researchers recently [11-13]. Xu et al. [14] employed X-ray computed tomography technology (CT technology) to obtain and analyze internal images of asphalt mixture under different freeze-thaw cycles and investigated the influences of freeze-thaw cycles on the evolution of internal air voids. Moreover, Xu et al. [15] investigated the effects of freeze-thaw cycles on the thermodynamic characteristics of asphalt mixtures, based on the information entropy theory, $\mathrm{CT}$, and digital image processing (DIP) technologies. Moreover, the influence of freeze-thaw cycles on permeability of asphalt mixtures were also evaluated by the means of flow state, as well as water conductivity, of asphalt mixtures [16]. Yan et al. [17] investigated stone matrix asphalt (SMA) mixtures under the effect of freeze-thaw 
cycles and evaluated the freeze-thaw resistance based on Marshall design indicators and water stability. Badeli et al. [18] conducted a rapid freeze-thaw cycle test for an asphalt mixture using thermomechanical tests.

Many researchers have also made efforts regarding freeze-thaw damage models of asphalt mixtures [19-21]. Tan et al. [22] investigated a freeze-thaw damage model and residual life prediction of asphalt mixture, based on damage theory, and they considered the compressive modulus as the index to evaluate freeze-thaw resistance and residual life prediction of an asphalt mixture under freeze-thaw cycles. Yi et al. [23] established generalized Maxwell and Drucker-Prager models to evaluate the viscoelastic-plastic damage under the condition of freeze-thaw cycles. A uniaxial compressive strength test was carried out to investigate the mechanisms of freeze-thaw failure in asphalt mixtures. Zhang [24] established a series of logistic damage models for different kinds of asphalt mixtures under the effects of water, temperature, and radiation to quantificationally analyze the damage degree of asphalt mixtures.

Fibers additives, such as cellulose fiber, polyester fiber, mineral fiber, etc., have been added into bitumen and proven as effective reinforcement materials for asphalt mixtures [25-28]. Imaninasab [29] investigated the effect of granular polymers on the rutting performance of stone matrix asphalt (SMA) compared with styrene-butadiene-styrene (SBS) modified and unmodified mixtures. Wang et al. [30] carried out many tests including indirect tensile strength, indirect tensile stiffness modulus, and dynamic shear rheological for polymer modified asphalt, in order to examine if the polymer modified asphalt has not been severely degraded. Hajikarimi et al. [31] used a dynamic shear rheometer to investigate the effect of polyphosphoric acid (PPA) and styrene-butadiene-styrene (SBS) modifications on the rheological and mechanical behavior of asphalt binders and asphalt mastics. Hajikarimi et al. [32] adopted a biphasic finite-element method to simulate an asphalt mastic as a heterogeneous medium consisting of aggregate particles, as inclusions within the asphalt binder, as the matrix for PPA and SBS. Basalt fiber, as a novel kind of eco-friendly mineral fiber, was produced from basalt rocks with high mechanical properties, low water absorption, and its by-products can be degraded directly in the environment without any harm [33]. Wang et al. [34,35] added basalt fiber into asphalt materials and evaluated their fatigue resistance by using direct tension, as well as fatigue tests. By means of X-ray tomography technology (i.e., CT technology) and the finite-element method, basalt fiber can release stress concentrations in critical areas and reduce fatigue damage. Gu et al. [36] compared and discussed basalt fiber and commonly used fibers and found that basalt fiber has a superior reinforcement effect on the high-temperature anti-rutting ability of bitumen mastic. Qin et al. [37] tested the reinforcement effects of basalt fibers with lengths of $3 \mathrm{~mm}, 6 \mathrm{~mm}$, and $9 \mathrm{~mm}$ for asphalt mastics, with respect to lignin fiber and polyester fiber. Through leakage, penetration, strip-tensile, and dynamic shear rheometer (DSR) tests, basalt fiber, especially with length of $6 \mathrm{~mm}$, has excellent comprehensive performances, due to a steady 3D networking structure in bitumen mastics. Zhang et al. [38] carried out repeated and multi-stress creep tests and used Abaqus software for analyzing the high-temperature performance of an asphalt mastic. Then Zhang et al. [39,40] conducted numerical simulations in Abaqus for compressive creep and bending creep tests, for the purpose of analyzing the distribution effect and reinforcement mechanism of basalt fiber. Wang et al. [41] explored the optimization design of SBS modified asphalt mixtures containing basalt fiber with the assistance of the central composite design method. Test results indicated that asphalt mixtures with a basalt fiber content of $0.34 \%$ and a length of $6 \mathrm{~mm}$ exhibited superior Marshall properties. Previous studies indicated that basalt fiber was effective in improving the mechanical properties of asphalt materials. Nevertheless, efforts undertaken for asphalt mixtures with basalt fiber under freeze-thaw cycles are still limited in this area.

In this present paper, freeze-thaw cycles were performed for asphalt mixtures reinforced with eco-friendly basalt fiber. The volume and mechanical properties (i.e., air voids, splitting tensile strength and indirect tensile stiffness modulus) of asphalt mixtures were adopted for freeze-thaw damage analysis. Furthermore, this study developed the logistic damage models of asphalt mixtures. in terms of the damage characteristics of the volume and mechanical properties. in order to quantificationally 
analyze the damage degree and damage grow rate. Subsequently, multi-variable grey models (GM) $(1, \mathrm{~N})$ were established for modelling the damage characteristics of the asphalt mixtures under the action of freeze-thaw cycles.

\section{Raw Materials, Experimental Methods and Theory Background}

\subsection{Raw Materials and Specimen Preparation}

\subsubsection{Raw Materials}

In this study, asphalt of AH-90 produced from PetroChina Liaohe Petrochemical Company (Panjin, China) in Liaoning Province was selected, and the corresponding basic physical performances are presented in Table 1. Then, andesite mineral aggregates from a local quarry in Changchun, Jilin Province and limestone powder were chosen for the asphalt mixture. Additionally, basalt fiber was obtained from Jiuxin Basalt Industry Co., Ltd. (Changchun, China). The detailed physical properties of the aggregates and basalt fiber have been given in the previous study [5].

Table 1. Physical properties of asphalt AH-90 in this study.

\begin{tabular}{ccc}
\hline Properties & Measurement & Technical Criterion \\
\hline Penetration @ 25 ${ }^{\circ} \mathrm{C}, 100 \mathrm{~g}, 5 \mathrm{~s}(0.1 \mathrm{~mm})$ & 88 & $80 \sim 100$ \\
Softening point $\left({ }^{\circ} \mathrm{C}\right)$ & 47 & $\geq 44$ \\
Ductility @ $10^{\circ} \mathrm{C}, 5 \mathrm{~cm} / \mathrm{min}(\mathrm{cm})$ & 43.5 & $\geq 30$ \\
Solubility (trichloroethylene, \%) & 99.8 & $\geq 99.5$ \\
Density @ $15^{\circ} \mathrm{C}\left(\mathrm{g} / \mathrm{cm}^{3}\right)$ & 1.05 & - \\
& RTFOT & \pm 0.8 \\
Mass loss $(\%)$ & 0.22 & $\geq 57$ \\
Penetration ratio @ $25^{\circ} \mathrm{C}(\%)$ & 66 & $\geq 8$ \\
\hline Ductility @ $10^{\circ} \mathrm{C}, 5 \mathrm{~cm} / \mathrm{min}(\mathrm{cm})$ & 28 & \\
\hline
\end{tabular}

\subsubsection{Specimen Preparation}

Traditional dense-graded asphalt mixture is a well-graded asphalt mixture and is applied extensively in asphalt pavement construction in China [42]. In this study, the median gradation of asphalt mixture (AC-13) was selected, as shown in Figure 1, and the upper and lower limits of AC-13 are also illustrated. Asphalt mixtures reinforced with eco-friendly basalt fiber were made by a standard Marshall design method [43,44] approximately $0.4 \%$ basalt fiber with a length of $6 \mathrm{~mm}$ was added into asphalt mixtures. In accordance to JTG E20-2011 [45], the detailed preparation procedures are presented as follows:

- Step (1): the pre-heated aggregates and basalt fiber were mixed together in a mixing pot for $90 \mathrm{~s}$ in order to make basalt fiber uniformly dispersed in aggregates.

- Step (2): the pre-heated asphalt AH-90 was weighted and poured into the mixing pot and the mixture was blended for $90 \mathrm{~s}$.

- $\quad$ Step (3): the pre-weighted limestone powder was added into the mixing pot and then blended for $90 \mathrm{~s}$.

- Step (4): Marshall specimens of AC-13 with a diameter of $101.6 \mathrm{~mm}$ and a height of $63.5 \mathrm{~mm}$ were prepared by compacting 75 blows on each side. 


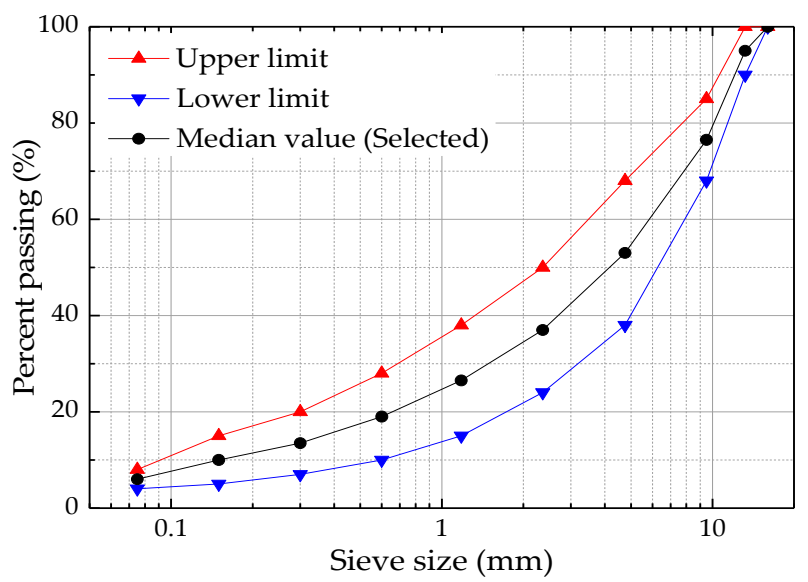

Figure 1. Gradation of asphalt mixture used in this study [5].

\subsection{Freeze-Thaw Cycle Procedure}

Figure 2 gives a detailed description of the freeze-thaw cycles in this study, in which the real simulation is shown in Figure 2a, and the one-time freeze-thaw cycle in the laboratory is shown in Figure $2 \mathrm{~b}$. Before the freeze-thaw cycle test, specimens were immersed into water and under vacuum $(98.0 \mathrm{kPa})$ for $15 \mathrm{~min}$, and soaked under atmospheric pressure for $30 \mathrm{~min}$. Then, a one-time freeze-thaw cycle was carried out on specimens, in which the freezing condition of the refrigerator was set as $-18^{\circ} \mathrm{C}$ for $16 \mathrm{~h}$, and the thaw condition of the thermostatic waterbath was in water at $60^{\circ} \mathrm{C}$ for $8 \mathrm{~h}$. A number of 84 specimens were treated for the freeze-thaw cycle test, in which each freeze-thaw cycle had 3 replicates. After 0, 1, 3, 6, 9, 12, and 15 freeze-thaw cycles, the experimental tests were carried out for asphalt mixtures.

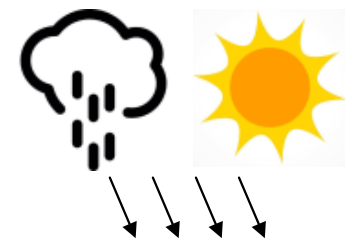

Water permeated into asphalt pavement

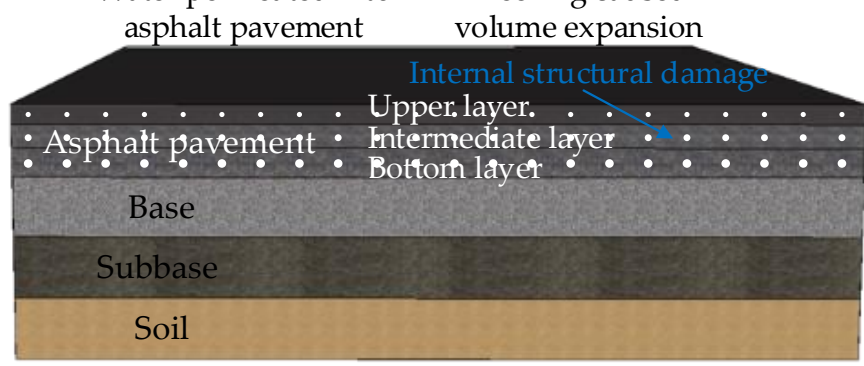

(a)

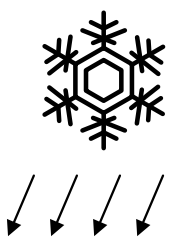

Freezing caused volume expansion

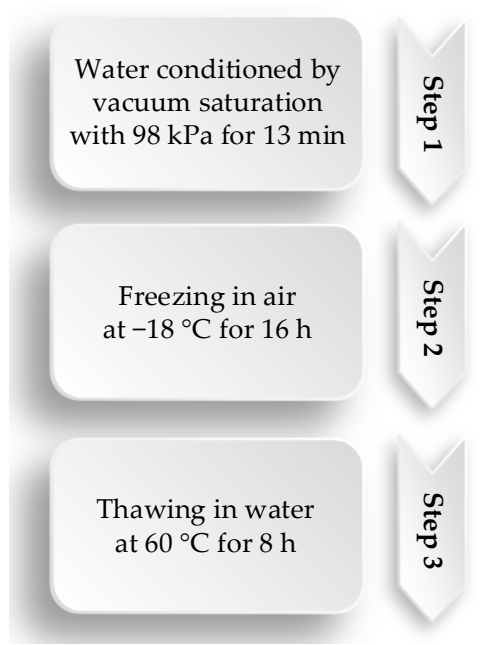

(b)

Figure 2. Freeze-thaw cycle in this study (a) schematic diagram; (b) experimental procedure.

\subsection{Damage Characteristics Indicators}

\subsubsection{Air Voids}

Air voids are one of the key indicators for characterizing the quality of asphalt pavement. Almost all performances of asphalt pavement, like cracking resistance, anti-rutting, fatigue resistance, etc., are closely related to air voids. Asphalt pavement with higher air voids would incur many distresses, such as spalling, crumbling, pumping, and so on. However, lower air voids may lead to rutting and extensive oil, etc. Thus, an air voids indicator was selected to characterize the freeze-thaw 
damage in this study. In accordance to T0709 JTG E20-2011 [45], air voids (VA) can be determined through weighting asphalt mixture specimens in air and water at room temperature, following the Equations (1) and (2):

$$
\begin{gathered}
\gamma_{f}=m_{a} /\left(m_{f}-m_{w}\right), \\
V A=\left[1-\gamma_{f} / \gamma_{T M D}\right] \times 100,
\end{gathered}
$$

where $m_{a}, m_{w}$ and $m_{f}$ represent the mass of specimens in air, water, and the saturated surface dry mass, respectively. $\gamma_{f}$ is the bulk specific gravity and $\gamma_{T M D}$ is the theoretical maximum specific density which can be measured by vacuum sealing method.

\subsubsection{Splitting Tensile Strength}

A splitting test reflects mechanical performance at the moment of splitting, failure under specific temperature, and loading rate. Splitting tensile strength (STS) is considered as an effective indicator for asphalt mixture, and it is also widely used in many studies [46,47]. According to T0716 in JTG E20-2011 [45], the splitting tensile strength test shown in Figure 3 was performed at $15{ }^{\circ} \mathrm{C}$ by the Marshall apparatus, with a load of speed of $50 \mathrm{~mm} / \mathrm{min}$ until the specimen was broken. The deformation was measured by linear variable differential transformers (LVDT). Then, the splitting tensile strength was calculated by the following equation:

$$
R_{\mathrm{T} 1}=0.006287 \times P_{\mathrm{T} 1} / h_{1}
$$

where $R_{\mathrm{T} 1}$ is the splitting tensile strength, $P_{\mathrm{T} 1}$ is the maximum load, and $h_{1}$ is the specimen height.

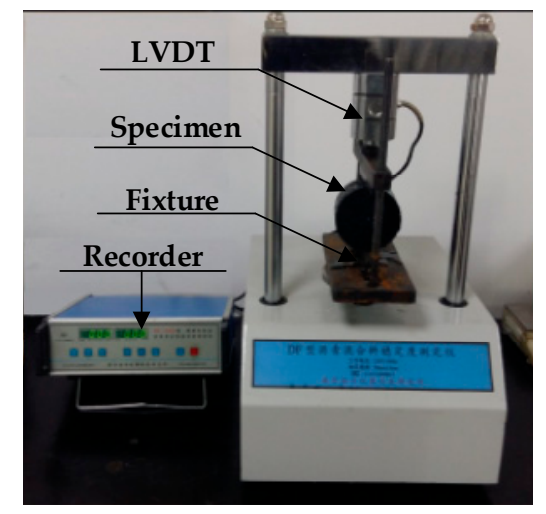

Figure 3. Splitting tensile strength test in this paper.

\subsubsection{Indirect Tensile Stiffness Modulus}

The indirect tensile stiffness modulus (ITSM) is an important indicator for evaluating mechanical performance. In this study, the ITSM test at $10^{\circ} \mathrm{C}$ was adopted and conducted according to the standard AASHTO TP-31 for evaluating the anti-crack ability of the asphalt mixture [48]. A servo-pneumatic universal testing machine, shown in Figure 4, was used for the ITSM test. Firstly, Marshall specimens were put into the environmental chamber at $10^{\circ} \mathrm{C}$ for at least 5 hours. Then, three replicate specimens were measured for ITSM. Then, ITSM $\left(S_{m}\right)$ values could be calculated as follows:

$$
S_{m}=F \times(\mu+0.27) /(h \times Z),
$$

where $F$ is the peak load $(\mathrm{N}), \mu$ is the Poisson ratio and $\mu=0.25$ at $10^{\circ} \mathrm{C}, h$ is the specimen height $(\mathrm{mm})$, and $Z$ is the horizontal deformation ( $\mathrm{mm}$ ). 


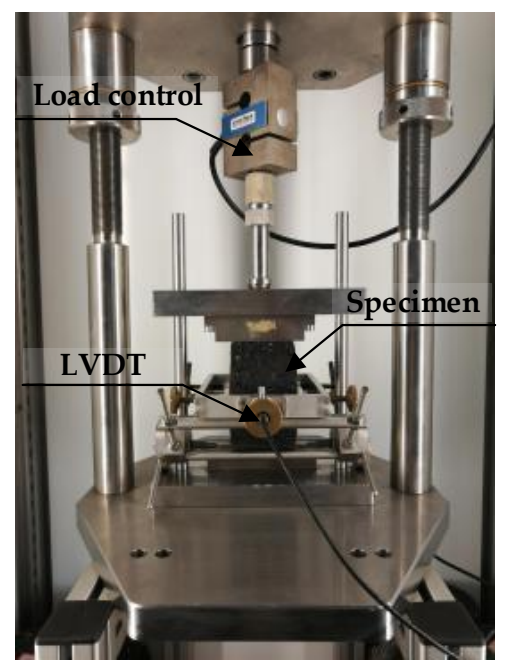

Figure 4. Indirect tensile stiffness modulus test in this study.

\subsection{Theory Background of Damage Model and Prediction Model}

\subsubsection{Logistic Damage Model}

A logistic model is a widely used non-linear statistical model, which is mainly used to discuss and quantify the relationship between the "damage" parameters and the independent variables for the calculation of damage probabilities [24]. The logistic model was developed from Malthus model expressed by Equation (5):

$$
\mathrm{d} N / \mathrm{d} t \times 1 / N=r,
$$

where $N$ is the dependent variable. $t$ is the independent variable, and $r$ is a constant.

Then the analytical solution of Equation (5) is given by

$$
N(t)=N_{0} \times e^{r t},
$$

on the basis of Malthus model, assuming that the model is linearly constrained gives

$$
\mathrm{d} N / \mathrm{d} t \times 1 / N=-r / Q \times N+r,
$$

where $Q$ is the saturation factor and $r$ is the growth rate factor.

Rewriting Equation (7) in the expression of logistic model gives

$$
\mathrm{d} N / \mathrm{d} t=r N \times(1-N / Q),
$$

the analytical solution of logistic model can be solved as

$$
N(t)=Q /\left[1+\left(Q-N_{0}\right) /\left(N_{0} \times e^{r t}\right)\right],
$$

Equation (9) can be rewritten as

$$
N(t)=Q /\left[1+e^{(a-r t)}\right],
$$

and the damage degree can be defined as

$$
D=\left(1-I_{i} / I_{0}\right) \times 100,
$$

where $D$ is the damage degree, $I_{0}$ is the initial index, and $I_{i}$ is the index of the $i$ th freeze-thaw cycle. 
Therefore, the damage degree in Equation (12), based on the logistic model, was established in order to analyze the freeze-thaw damage degree of asphalt mixtures.

$$
D=\left(A_{1}-A_{2}\right) /\left[1+\left(x / x_{0}\right)^{p}\right]+A_{2}
$$

where $A_{1}$ is the minimum value of regression curve, $A_{2}$ is the maximum value of regression curve, which reflects the degree of damage, and $x_{0}$ is the $\mathrm{x}$-coordinate value when $D=0.5 A_{2}$, which reflects the damage grow rate.

\subsubsection{Multi-Variable Grey Model Represented by GM $(1, \mathrm{~N})$}

The grey system is a widely known mathematical theory in various fields such as economics, engineering, etc., which can be used for cases with partially known information or lacking adequate experimental data [49-51]. In general, grey system theory is mainly utilized for two aspects, i.e., grey relational degree analysis (GRA) and grey prediction models (GM). GRA is usually applied for measuring the uncertain relationships between factors. Grey prediction models reveal long-term processes for the development of various factors, and it could be used a priori to predict a property's development with less priori data. In this study, a multi-variable grey model, GM $(1, \mathrm{~N})$, was adopted and established to predict the freeze-thaw damage of an asphalt mixture.

Considering that the grey model has $N$ variables, which is denoted by $y_{i}(i=1,2, \ldots, N)$ with $m$ initial sequences:

$$
y_{i}^{(0)}=\left\{y_{i}^{(0)}(1), y_{i}^{(0)}(2), \ldots, y_{i}^{(0)}(m),\right\},(i=1,2, \ldots, N),
$$

through 1-accumulated generating operation (1-AGO), the 1-AGO sequence of initial sequence can be obtained

$$
\begin{gathered}
y_{i}^{(1)}=\left\{y_{i}^{(1)}(1), y_{i}^{(1)}(2), \ldots, y_{i}^{(1)}(m),\right\},(i=1,2, \ldots, N) \\
y_{i}^{(1)}(t)=\sum_{j=1}^{t} y_{i}^{(0)}(j),(j=1,2, \ldots, m),
\end{gathered}
$$

the whitening differential equation of the grey model could be determined by

$$
\frac{d y_{1}^{(1)}(k)}{d t}+a y_{1}^{(1)}(k)=\sum_{i=2}^{n} b_{i} y_{i}^{(1)}(k)
$$

then the grey differential equation is written as follows:

$$
\begin{aligned}
& y_{1}^{(0)}(k)+a z_{1}^{(1)}(k)=\sum_{i=2}^{n} b_{i} y_{i}^{(1)}(k), \\
& z_{1}^{(1)}(k)=\frac{y_{1}^{(1)}(k)+y_{1}^{(1)}(k-1)}{2} .
\end{aligned}
$$

In GM $(1, N)$, the grey parameter $P_{N}$ can be obtained according to the least square method:

$$
\begin{gathered}
P_{N}=\left(B^{\mathrm{T}} B\right)^{-1} B^{\mathrm{T}} Y_{n} \\
B=\left[\begin{array}{cccc}
-z_{1}^{1}(2) & y_{2}^{(1)}(2) & \cdots & y_{n}^{(1)}(2) \\
-z_{1}^{1}(3) & y_{2}^{(1)}(3) & \cdots & y_{n}^{(1)}(3) \\
\vdots & \vdots & & \vdots \\
-z_{1}^{1}(m) & y_{2}^{(1)}(m) & \cdots & y_{n}^{(1)}(m)
\end{array}\right], \\
y_{n}=\left[\begin{array}{llll}
y_{1}^{(0)}(2) & y_{1}^{(0)}(3) & \cdots & y_{1}^{(0)}(m)
\end{array}\right]^{-1},
\end{gathered}
$$


substituting $P_{N}$ in the Equation (19) into the Equation (16) gives

$$
\hat{y}_{1}^{(1)}(k+1)=\left(y_{1}^{(0)}(1)-\sum_{i=2}^{n-1} \frac{b_{i} y_{i}^{(1)}(k+1)}{a}\right) e^{-a t}+\sum_{i=2}^{n-1} \frac{b_{i} y_{i}^{(1)}(k+1)}{a},
$$

therefore, the $(k+1)$-th predictive value can be obtained by an inverse accumulated generating operation.

$$
\hat{y}_{1}^{(0)}(k+1)=\hat{y}_{1}^{(1)}(k+1)-\hat{y}_{1}^{(1)}(k)
$$

\section{Results and Discussion}

\subsection{Logistic Damage Model of Asphalt Mixtures under Freeze-Thaw Cycles}

To illustrate the effects of eco-friendly basalt fiber on the performance of an asphalt mixture, a series of experiments was carried out for two kinds of asphalt mixtures, i.e., the control group (AM, asphalt mixtures without basalt fiber) and test group (BFAM, asphalt mixture with basalt fiber). The freeze-thaw damage can be characterized by air voids (VA) for the volume parameter, splitting tensile strength (STS), and indirect tensile stiffness modulus (ITSM) for mechanical parameters. Therefore, the damage degrees of VA, STS, and ITSM were adopted as the evaluating indicators of asphalt mixture under various freeze-thaw cycles.

The VA, STS, and ITSM of AM and BFAM varying with freeze-thaw cycles are plotted in Figure $5 \mathrm{a}, \mathrm{c}, \mathrm{e}$, and the corresponding damage degree results are shown in Figure $5 \mathrm{~b}, \mathrm{~d}, \mathrm{f}$, in which the logistic models are expressed in curves with uncertain data. Based on the logistic damage model theory in the Section 2.4.1, the logistic damage models of VA, STS, and ITSM for AM and BFAM could be established and listed in Table 2. These logistic damage models could be proven effective, due to the higher correlation coefficients $\mathrm{R}^{2}$ above 0.97 and Adj. R-Squared values in Table 2 represent the fitting parameter accuracy. As plotted in Figure $5 a, c, e$, it can be clearly seen that the VA results of asphalt mixtures gradually increased with the increasing of the freeze-thaw cycles, whereas the STS and ITSM results presented a decreasing trend. Simultaneously, Figure $5 b, d, f$ illustrate that asphalt mixtures were gradually damaged with freeze-thaw cycles. Furthermore, the variation trend of the damage degree of the asphalt mixtures increased rapidly at first and then more slowly. Under the action of freeze-thaw cycles, the internal structure of asphalt mixtures was damaged due to volume expansion and temperature stress. The adhesion capability between asphalt and aggregates became weaker and weaker under the continuous action of freeze-thaw cycles. Before 9 freeze-thaw cycles, the air voids in asphalt mixture first extended and then, adjacent air voids were coalesced, leading to the significant variation trend. However, the expansion and formation of air voids became slow after 9 freeze-thaw cycles.

In addition, by comparative analysis of control and test groups, the addition of basalt fiber can significantly improve the STS and ITSM, and decline the VA of asphalt mixture. Meanwhile, the damage degree of eco-friendly basalt fiber modified asphalt mixture has been as well greatly reduced. This may be owing to the fact that the basalt fiber formed a spatial networking structure, playing the role of reinforcement and toughening. Due to the poor absorption of water, but good adhesiveness with asphalt for basalt fiber, basalt fiber can also limit shrinkage cracking due to temperature stress under freeze-thaw cycles. From Table 2, by comparative analysis of the damage characteristics (i.e., VA, STS, and ITSM) of two kinds of asphalt mixtures, i.e., ordinary asphalt mixture (AM) and basalt fiber modified asphalt mixture (BFAM), it clearly shows that the model parameter " $A_{2}$ " values of the logistic damage model of AM are always more than those of BFAM. Furthermore, the model parameter " $x_{0}$ " values of AM are higher than those of BFAM at all times. The variations of the model parameters between those asphalt mixtures quantificationally demonstrate that the addition of basalt fiber into an asphalt mixture can significantly reduce the damage degree of asphalt mixtures and slow down the damage grow rate. 


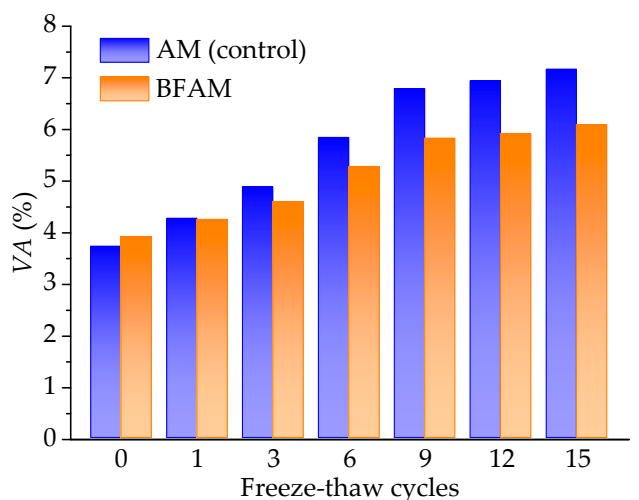

(a)

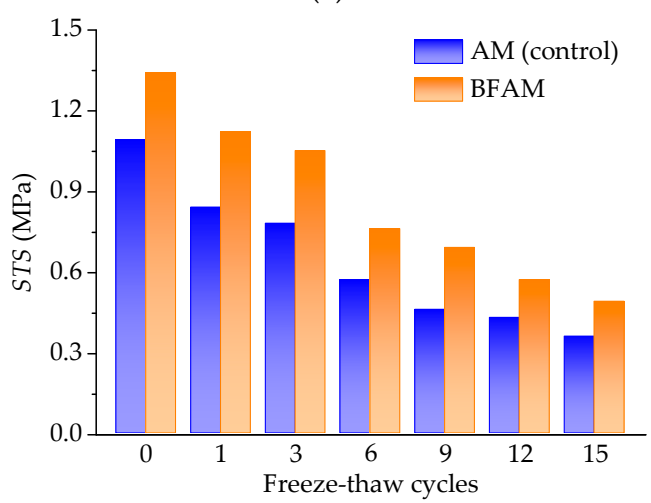

(c)

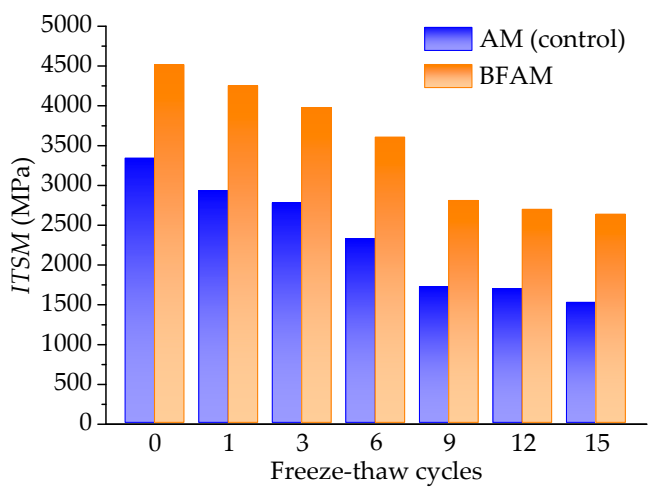

(e)

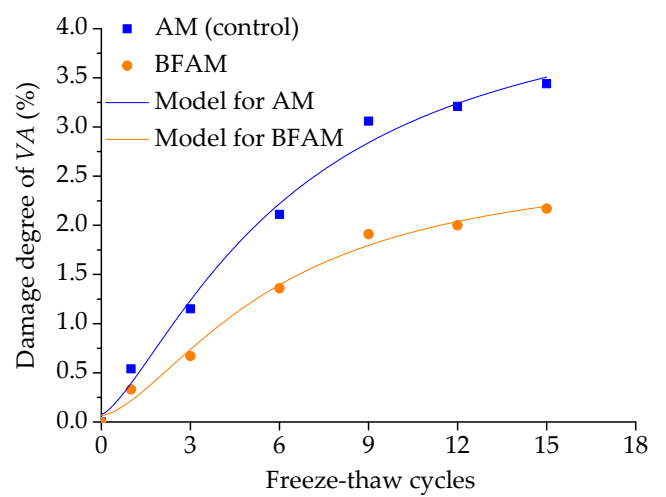

(b)

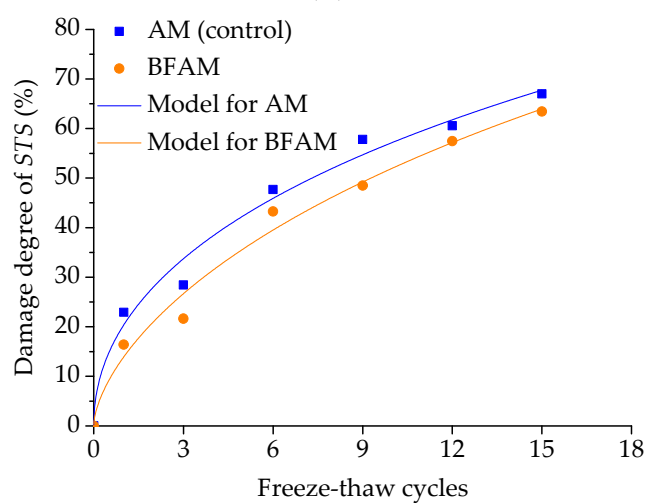

(d)

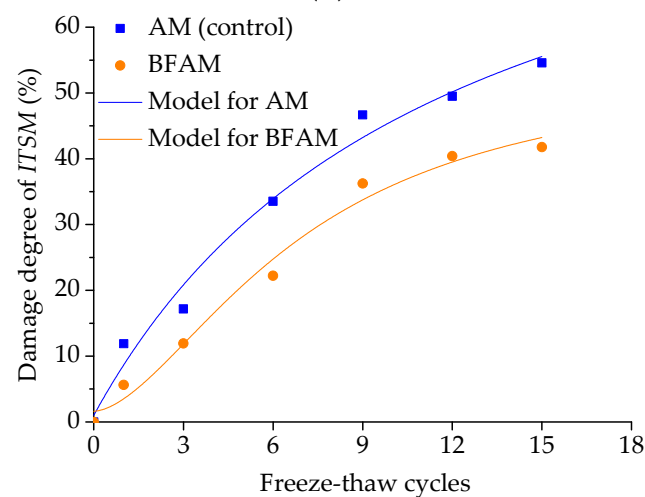

(f)

Figure 5. The relationships between damage characteristics of asphalt mixture and freeze-thaw cycles: (a) air voids (VA); (b) Damage degree of VA; (c) splitting tensile strength (STS); (d) Damage degree of STS; (e) indirect tensile stiffness modulus (ITSM); (f) Damage degree of ITSM.

Table 2. Logistic damage model of asphalt mixtures under freeze-thaw cycles.

\begin{tabular}{cccc}
\hline $\begin{array}{c}\text { Damage } \\
\text { Characteristics }\end{array}$ & $\begin{array}{c}\text { Mixture } \\
\text { Type }\end{array}$ & $\begin{array}{c}\text { Logistic Damage Model } \\
\left(\boldsymbol{D}=\left(\boldsymbol{A}_{\mathbf{1}}-\boldsymbol{A}_{\mathbf{2}}\right) /\left[\mathbf{1}+\left(x / \boldsymbol{x}_{\mathbf{0}}\right)^{p}\right]+\boldsymbol{A}_{\mathbf{2}}\right)\end{array}$ & $\begin{array}{c}\text { Adj. } \\
\text { R-Squared }\end{array}$ \\
\hline \multirow{2}{*}{$V A$} & AM & $D=(0.08-4.55) /\left[1+(x / 6.37)^{1.39}\right]+4.55$ & 0.9824 \\
& BFAM & $D=(0.07-2.68) /\left[1+(x / 5.87)^{1.58}\right]+2.68$ & 0.9834 \\
STS & AM & $D=(0.23-395.54) /\left[1+(x / 360.86)^{0.50}\right]+395.54$ & 0.9721 \\
& BFAM & $D=(0.35-271.72) /\left[1+(x / 92.51)^{0.65}\right]+271.72$ & 0.9717 \\
ITSM & AM & $D=(1.02-97.95) /\left[1+(x / 11.67)^{1.00}\right]+97.95$ & 0.9714 \\
& BFAM & $D=(1.63-54.53) /\left[1+(x / 6.96)^{1.70}\right]+54.53$ & 0.9746 \\
\hline
\end{tabular}




\subsection{Freeze-Thaw Damage Prediction Model Based on Grey Model by GM $(1, N)$}

In order to illustrate the multi-variable grey model GM $(1, N)$ in this study, the cases for damage characteristics of asphalt mixtures under the actions of $0 \sim 15$ freeze-thaw cycles have been investigated to validate the feasibility and accuracy of GM $(1, N)$, based on the experimental data of damage characteristics under limited freeze-thaw cycles. Through different combinations of the damage degrees of VA, STS, and ITSM, three GM $(1,2)$ could be established, at the same time, the GM $(1,3)$ could be established according to the damage degrees of VA, STS, and ITSM.

\subsubsection{Two-Variable Grey Model GM $(1,2)$}

Based on the damage degrees of VA, STS, and ITSM, three two-variable grey models could be established, i.e., GM $(1,2)$ of VA and STS (as show in Figure 6), VA and ITSM (as show in Figure 7), STS and ITSM (as show in Figure 8). Ren found that the more samples do not necessarily mean the more accurate prediction of a grey model $[50,51]$. Accordingly, these GM $(1,2)$ were established in terms of the experimental data under $0 \sim 9$ freeze-thaw cycles, and the experimental data under 12 and 15 freeze-thaw cycles were used to verify the established GM $(1,2)$.

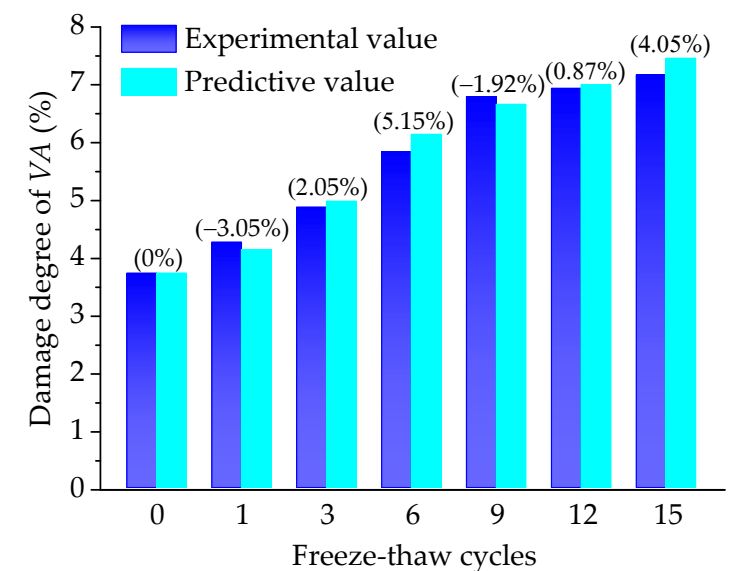

(a)

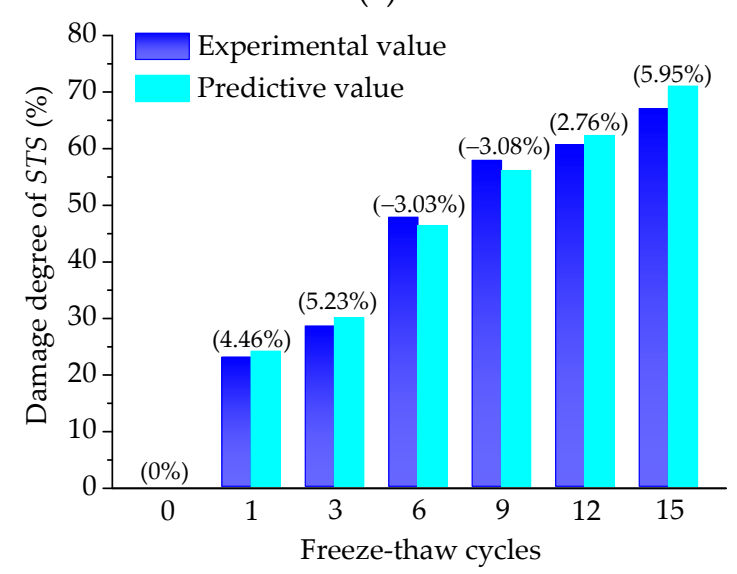

(c)

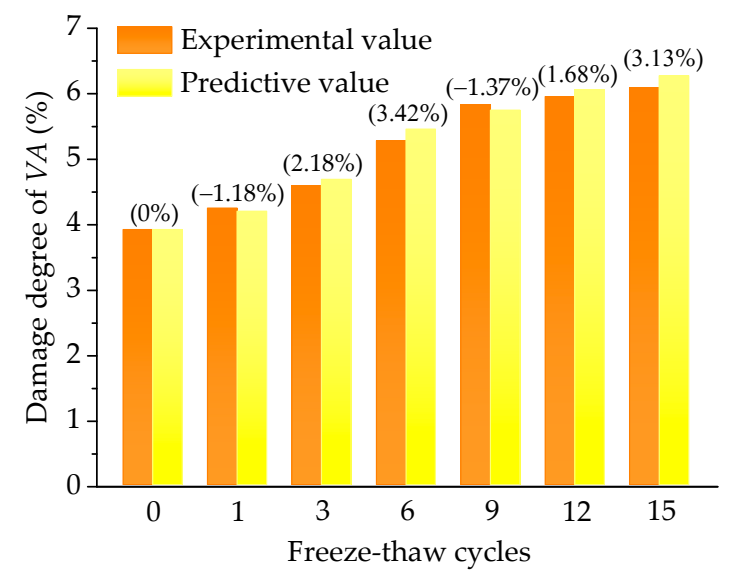

(b)

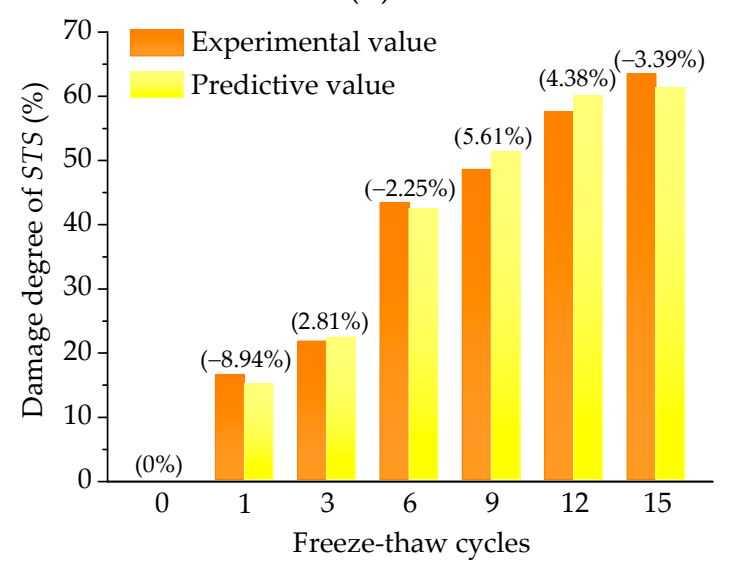

(d)

Figure 6. Comparison between predictive and experimental values for asphalt mixtures without basalt fiber (AM) and asphalt mixtures with basalt fiber (BFAM) based on GM $(1,2)$ of VA and STS tests: (a) Damage degree of VA for AM; (b) Damage degree of VA for BFAM; (c) Damage degree of STS for AM; (d) Damage degree of STS for BFAM. 


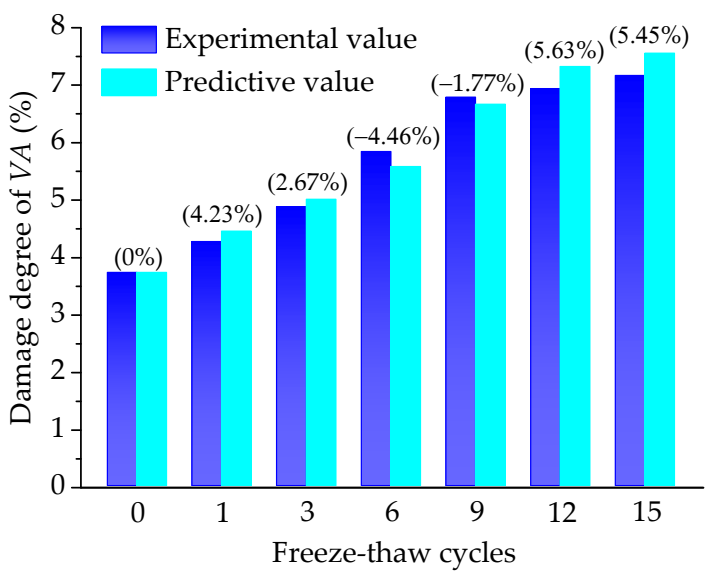

(a)

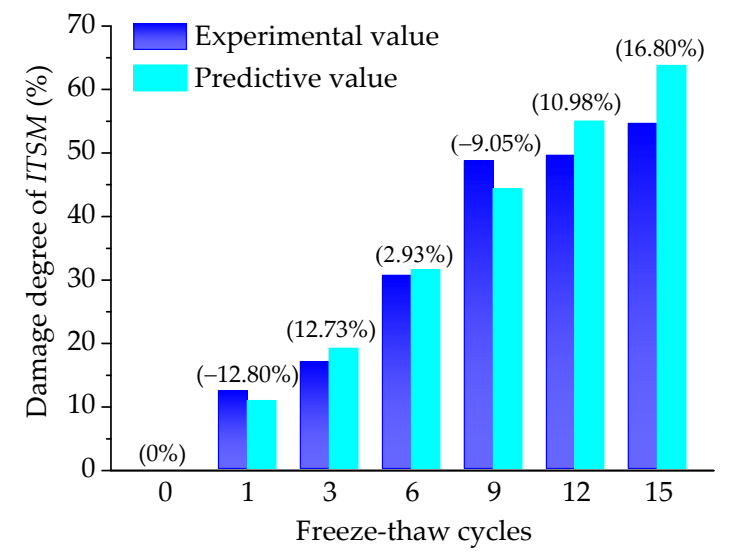

(c)

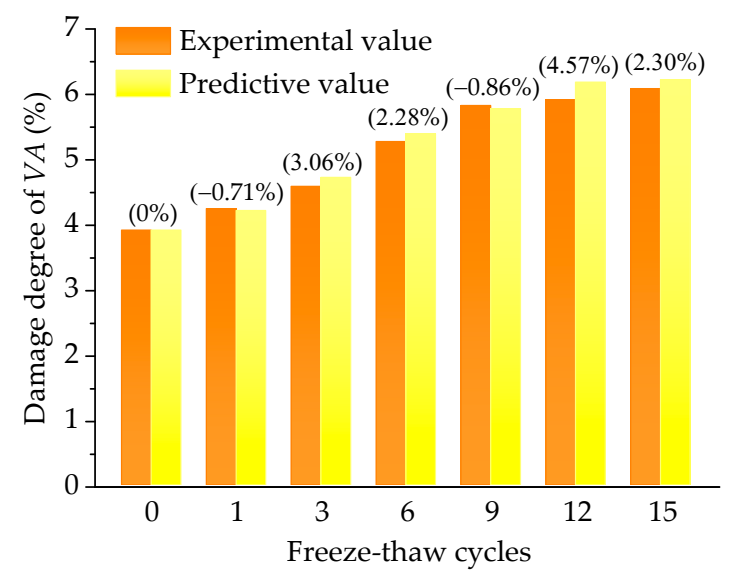

(b)

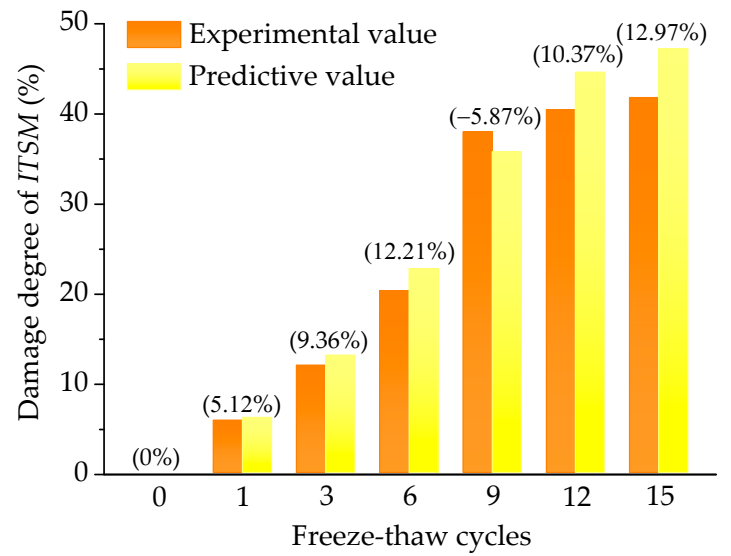

(d)

Figure 7. Comparison between predictive and experimental values for AM and BFAM based on GM $(1,2)$ of VA and ITSM tests: (a) Damage degree of VA for AM; (b) Damage degree of VA for BFAM; (c) Damage degree of ITSM for AM; (d) Damage degree of ITSM for BFAM.

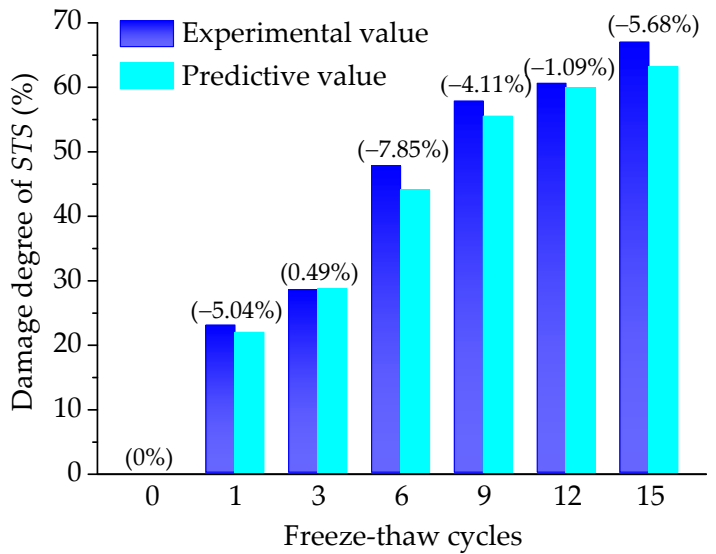

(a)

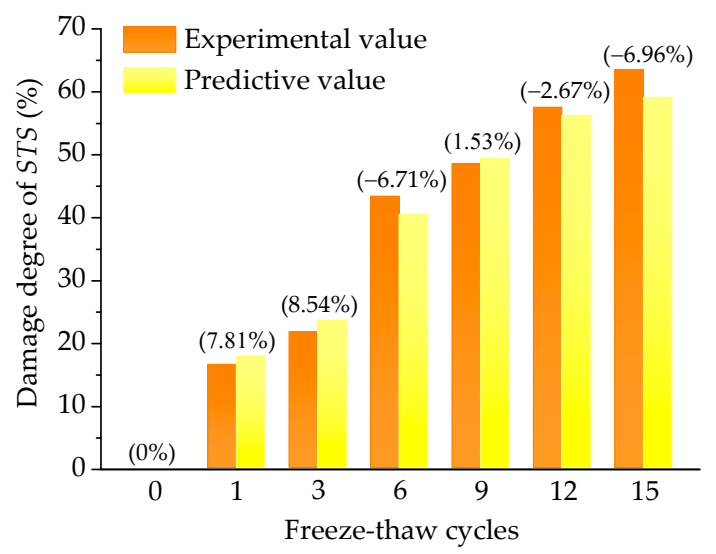

(b)

Figure 8. Cont. 


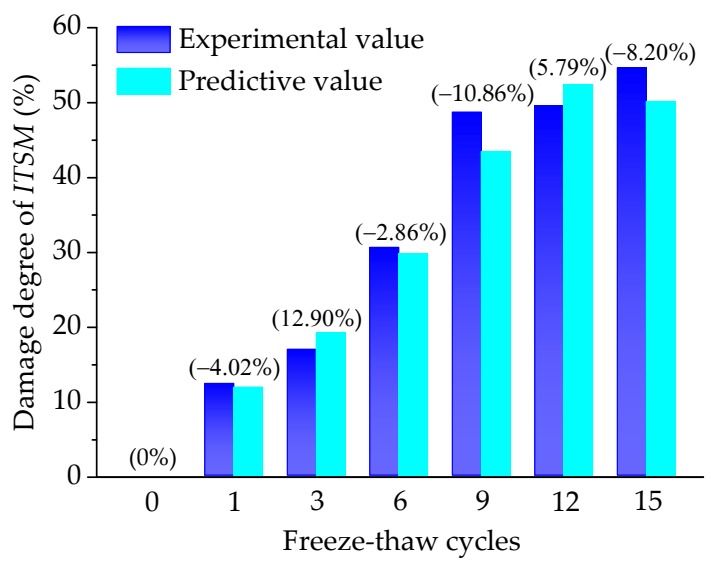

(c)

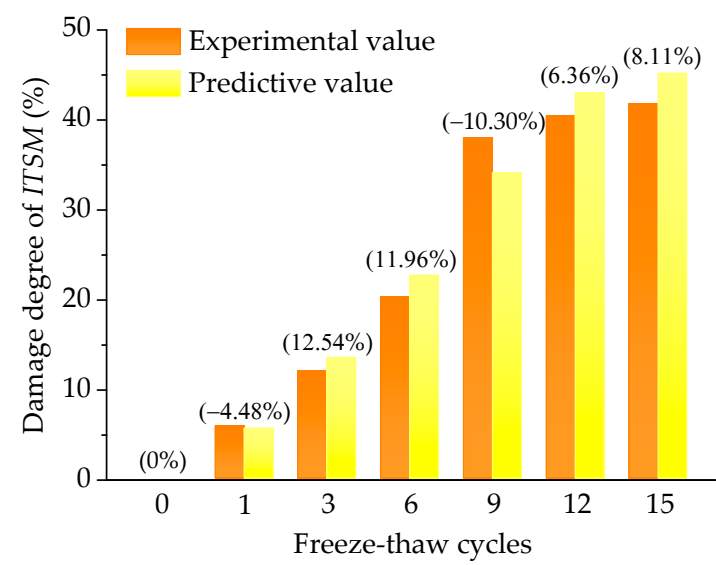

(d)

Figure 8. Comparison between predictive and experimental values for AM and BFAM based on GM $(1,2)$ of STS and ITSM tests: (a) Damage degree of STS for AM; (b) Damage degree of STS for BFAM;

(c) Damage degree of ITSM for AM; (d) Damage degree of ITSM for BFAM.

The predictive values of VA and STS compared with the experimental results are presented in Figure 6 , based on the grey model GM $(1,2)$ of $V A$ and $S T S$ tests. It is apparent that the relative errors for $V A$ of AM and BFAM are within $6 \%$, and the relative errors of STS of AM and BFAM are around $10 \%$.

The predictive values of VA and ITSM compared with the experimental results are presented in Figure 7 , based on the grey model GM $(1,2)$ of VA and ITSM tests. It is apparent that the relative errors for VA of AM and BFAM are around 6\%, and the relative errors of ITSM of AM and BFAM are within $17 \%$.

The predictive values of STS and ITSM compared with the experimental results are presented in Figure 8, based on the grey model GM $(1,2)$ of STS and ITSM tests. It is apparent that the relative errors for STS of AM and BFAM are within 9\%, and the relative errors of ITSM of AM and BFAM are around $13 \%$.

\subsubsection{Three-Variable Grey Model GM (1,3)}

To study the number of independent variables for the prediction accuracy of GM $(1, N)$, the three-variable grey model GM $(1,3)$ was also built according to the experimental data under $0 \sim 9$ freeze-thaw cycles, to predict the damage characteristics under 12 and 15 freeze-thaw cycles for verification.

The predictive values of VA, STS, and ITSM compared with the experimental results are presented in Figure 9 based on the three-variable grey model GM $(1,3)$ of VA, STS, and ITSM tests. It is apparent that the relative errors for $V A$ of $A M$ and BFAM are within 3\%, the relative errors for STS of AM and BFAM are within $6 \%$, and the relative errors of ITSM of AM and BFAM are around $8 \%$. Compared with two-variable GM $(1,2)$ in Section 3.2.1, the results revealed that the relative error of three-variable GM $(1,3)$ is smaller than that of GM $(1,2)$ for the aspect of prediction accuracy. Thus, to some degree, it could be indicated that GM $(1,3)$ has the better prediction accuracy than GM $(1,2)$ under the conditions of the same data.

Through overall consideration, the three-variable grey model GM $(1,3)$ based on VA, STS, and ITSM tests is an effective prediction model for asphalt mixtures under the action of freeze-thaw cycles, which can reflect the evolution of freeze-thaw damage for asphalt mixtures more accurately. 


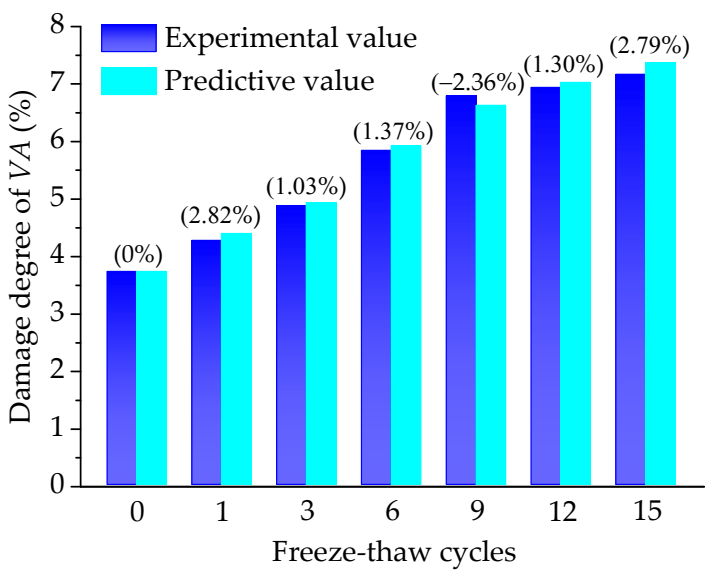

(a)

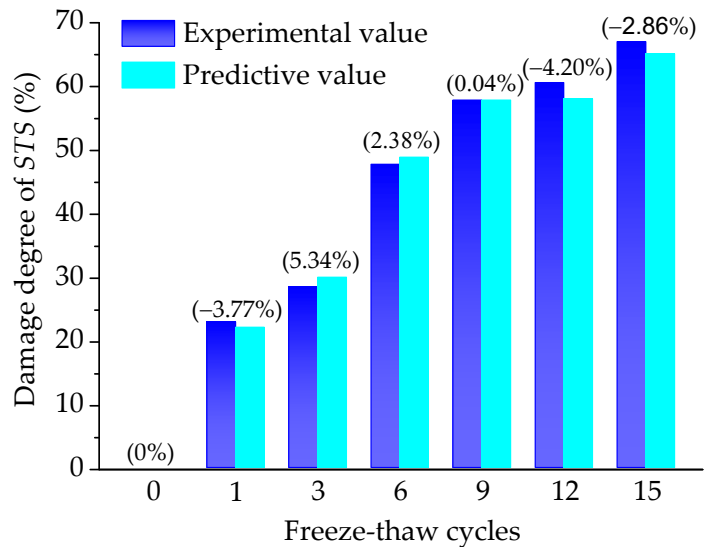

(c)

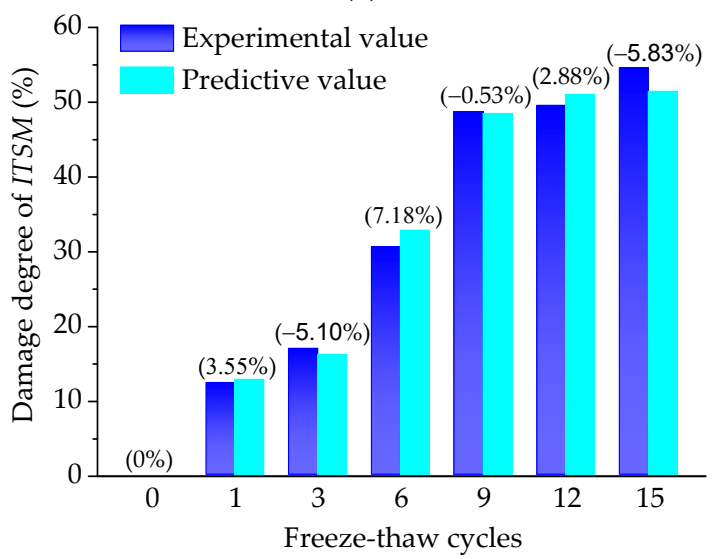

(e)

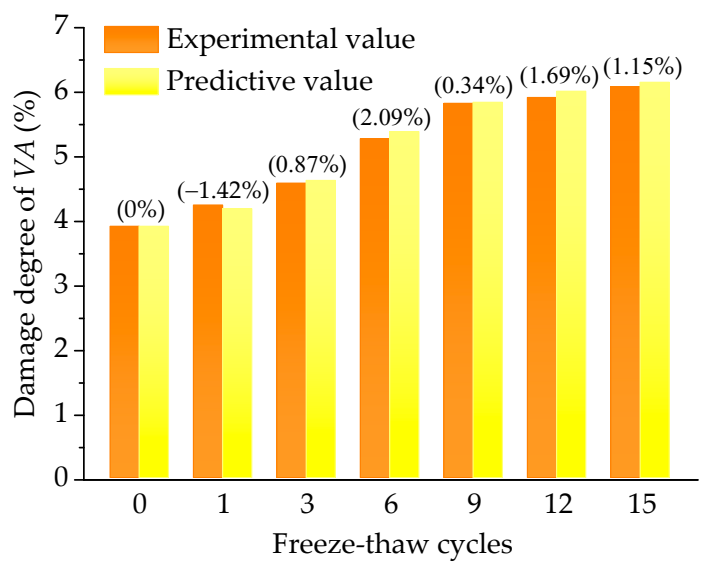

(b)

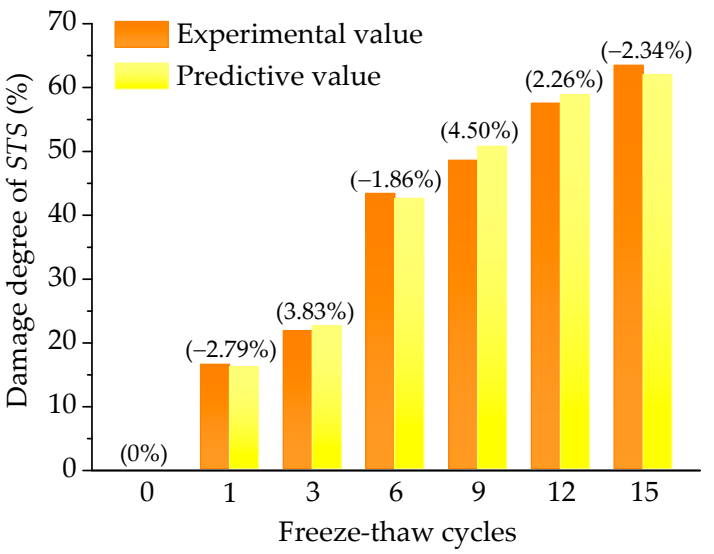

(d)

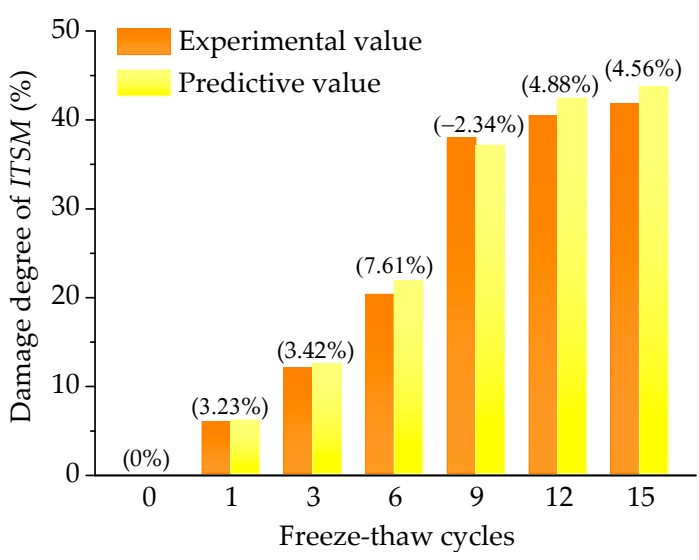

(f)

Figure 9. Comparison between predictive and experimental values for AM and BFAM based on GM $(1,3)$ of VA, STS, and ITSM tests: (a) Damage degree of VA for AM; (b) Damage degree of VA for BFAM; (c) Damage degree of STS for AM; (d) Damage degree of STS for BFAM; (e) Damage degree of ITSM for AM; (f) Damage degree of ITSM for BFAM.

\section{Conclusions}

This study further explored the freeze-thaw damage characteristics of asphalt mixtures reinforced with eco-friendly basalt fiber through air voids, splitting tensile strength, and indirect tensile stiffness modulus tests. Based on the damage characteristics, a logistic damage model was established to quantificationally analyze the damage degree and damage grow rate of asphalt mixtures. Additionally, 
multi-variable grey models were established for modelling the freeze-thaw damage characteristics of asphalt mixtures. Thus, the following conclusions can be drawn:

- Freeze-thaw cycles habr a negative effect on the volume and mechanical properties of an asphalt mixture. From air voids, splitting tensile strength, and indirect tensile stiffness modulus, the addition of basalt fiber can significantly improve the freeze-thaw resistance and mechanical performance of an asphalt mixture, leading to a reinforcement mechanism.

- The logistic damage model can quantificationally demonstrate that adding basalt fiber could significantly reduce the damage degree of asphalt mixtures by about $25 \%$, and slow down the damage grow rate by about $45 \%$ compared to a control group.

- The ninth freeze-thaw cycle may be the turning point of damage variation of an asphalt mixture, after which the expansion and formation of air voids became slower.

- Results demonstrated that the established multi-variable grey models can accurately predict the variation trend of damage characteristics of asphalt mixtures. GM $(1,3)$ was proven to perform better in prediction accuracy compared to $\operatorname{GM}(1,2)$ under the same data. GM $(1,3)$ is an effective prediction model for reflecting the evolution of freeze-thaw damage for asphalt mixtures.

- Appropriate basalt fiber content is recommended for modifying an asphalt mixture. It is necessary to check the dispersion of basalt fibers in an asphalt mixture to ensure the dispersion of basalt fiber. Compared to ordinary asphalt mixtures, the predicted cost is mainly reliant on the basalt fibers.

Author Contributions: Conceptualization, W.W. and Y.C.; Methodology, W.W. and G.T.; Validation, Y.C.; Formal Analysis, G.T. and G.M.; Investigation, W.W., G.M., X.S. and S.Y.; Writing-Original Draft Preparation, W.W.; Writing-Review \& Editing, Y.C.; Project Administration, G.T.; Funding Acquisition, G.T.

Funding: This research was funded by [National Natural Science Foundation of China] grant number [51678271], [Science Technology Development Program of Jilin Province] grant number [20160204008SF], supported by Graduate Innovation Fund of Jilin University grant number [101832018C003], [Transportation Science and Technology Program of Jilin Province] grant number [2018-1-9], [the Education Department's "13th Five-Year" Science and Technology Program of Jilin Province] grant number [JJKH20190015KJ].

Acknowledgments: The authors would like to appreciate anonymous reviewers for their constructive suggestions and comments to improve the quality of the paper.

Conflicts of Interest: The authors declare no conflict of interest.

\section{References}

1. Chen, M.Z.; Lin, J.T.; Wu, S.P. Potential of recycled fine aggregates powder as filler in asphalt mixture. Constr. Build. Mater. 2011, 25, 3909-3914. [CrossRef]

2. Zhang, R.; Dai, Q.L.; You, Z.P.; Wang, H.N.; Peng, C. Rheological Performance of Bio-Char Modified Asphalt with Different Particle Sizes. Appl. Sci. 2018, 8, 1665. [CrossRef]

3. Gao, J.F.; Wang, H.N.; Bu, Y.; You, Z.P.; Hasan, M.R.M.; Irfan, M. Effects of coarse aggregate angularity on the microstructure of asphalt mixture. Constr. Build. Mater. 2018, 183, 472-484. [CrossRef]

4. Peng, C.; Zhang, H.; You, Z.P.; Xu, F.; Jiang, G.S.; Lv, S.T.; Zhang, R.; Yang, H. Preparation and anti-icing properties of a superhydrophobic silicone coating on asphalt mixture. Constr. Build. Mater. 2018, 189, 227-235. [CrossRef]

5. Wang, W.S.; Cheng, Y.C.; Tan, G.J.; Tao, J.L. Analysis of Aggregate Morphological Characteristics for Viscoelastic Properties of Asphalt Mixes Using Simplex Lattice Design. Materials 2018, 11, 1908. [CrossRef] [PubMed]

6. Guo, Q.L.; Bian, Y.S.; Li, L.L.; Jiao, Y.B.; Tao, J.L.; Xiang, C.X. Stereo logical estimation of aggregate gradation using digital image of asphalt mixture. Constr. Build. Mater. 2015, 94, 458-466. [CrossRef]

7. Yang, X.; You, Z.P.; Hiller, J.; Watkins, D. Correlation Analysis between Temperature Indices and Flexible Pavement Distress Predictions Using Mechanistic-Empirical Design. J. Cold Reg. Eng. 2017, 31, 04017009. [CrossRef]

8. Lv, S.T.; Liu, C.C.; Zheng, J.L.; You, Z.P.; You, L.Y. Viscoelastic Fatigue Damage Properties of Asphalt Mixture with Different Aging Degrees. KSCE J. Civ. Eng. 2018, 22, 2073-2081. [CrossRef] 
9. Zhang, C.; Wang, H.N.; Yang, X.; You, Z.P. A Combinational Prediction Model for Transverse Crack of Asphalt Pavement. KSCE J. Civ. Eng. 2018, 22, 2109-2117. [CrossRef]

10. Feng, D.C.; Yi, J.Y.; Wang, D.S.; Chen, L.L. Impact of salt and freeze-thaw cycles on performance of asphalt mixtures in coastal frozen region of China. Cold. Reg. Sci. Technol. 2010, 62, 34-41. [CrossRef]

11. Pan, P.; Wu, S.P.; Hu, X.D.; Wang, P.; Liu, Q.T. Effect of freezing-thawing and ageing on thermal characteristics and mechanical properties of conductive asphalt concrete. Constr. Build. Mater. 2017, 140, 239-247. [CrossRef]

12. Badeli, S.; Carter, A.; Dore, G.; Saliani, S. Evaluation of the durability and the performance of an asphalt mix involving Aramid Pulp Fiber (APF): Complex modulus before and after freeze-thaw cycles, fatigue, and TSRST tests. Constr. Build. Mater. 2018, 174, 60-71. [CrossRef]

13. Zheng, Y.X.; Cai, Y.C.; Zhang, G.H.; Fang, H.Y. Fatigue Property of Basalt Fiber-Modified Asphalt Mixture under Complicated Environment. J. Wuhan. Univ. Technol. 2014, 29, 996-1004. [CrossRef]

14. Xu, H.N.; Guo, W.; Tan, Y.Q. Internal structure evolution of asphalt mixtures during freeze-thaw cycles. Mater. Des. 2015, 86, 436-446. [CrossRef]

15. Xu, H.N.; Li, H.Z.; Tan, Y.Q.; Wang, L.B.; Hou, Y. A Micro-Scale Investigation on the Behaviors of Asphalt Mixtures under Freeze-Thaw Cycles Using Entropy Theory and a Computerized Tomography Scanning Technique. Entropy 2018, 20, 68. [CrossRef]

16. Xu, H.N.; Guo, W.; Tan, Y.Q. Permeability of asphalt mixtures exposed to freeze-thaw cycles. Cold. Reg. Sci. Technol. 2016, 123, 99-106. [CrossRef]

17. Yan, K.Z.; Ge, D.D.; You, L.Y.; Wang, X.L. Laboratory investigation of the characteristics of SMA mixtures under freeze-thaw cycles. Cold Reg. Sci. Technol. 2015, 119, 68-74. [CrossRef]

18. Badeli, S.; Carter, A.; Dore, G. Complex Modulus and Fatigue Analysis of Asphalt Mix after Daily Rapid Freeze-Thaw Cycles. J. Mater. Civ. Eng. 2018, 30, 04018056. [CrossRef]

19. Liu, F.; You, Z.P.; Yang, X.; Wang, H.N. Macro-micro degradation process of fly ash concrete under alternation of freeze-thaw cycles subjected to sulfate and carbonation. Constr. Build. Mater. 2018, 181, 369-380. [CrossRef]

20. You, L.Y.; You, Z.P.; Dai, Q.L.; Guo, S.C.; Wang, J.Q.; Schultz, M. Characteristics of Water-Foamed Asphalt Mixture under Multiple Freeze-Thaw Cycles: Laboratory Evaluation. J. Mater. Civ. Eng. 2018, 30, 04018270. [CrossRef]

21. Huang, T.; Qi, S.; Yang, M.; Lv, S.T.; Liu, H.F.; Zheng, J.L. Strength Criterion of Asphalt Mixtures in Three-Dimensional Stress States under Freeze-Thaw Conditions. Appl. Sci. 2018, 8, 1302. [CrossRef]

22. Tan, Y.Q.; Zhao, L.D.; Lan, B.W.; Meng, L. Research on Freeze-thaw Damage Model and Life Prediction of Asphalt Mixture. J. Highw. Transport. Res. Dev. 2011, 6, 1-7. (In Chinese)

23. Yi, J.Y.; Shen, S.H.; Muhunthan, B.; Feng, D.C. Viscoelastic-plastic damage model for porous asphalt mixtures: Application to uniaxial compression and freeze-thaw damage. Mech. Mater. 2014, 70, 67-75. [CrossRef]

24. Zhang, P. Research on Characteristics and Detection Methods of Asphalt Mixture Damage Induced by Water-Temperature-Radiation. Ph.D. Thesis, Jilin University, Changchun, China, June 2015.

25. Ye, Q.S.; Wu, S.P.; Li, N. Investigation of the dynamic and fatigue properties of fiber-modified asphalt mixtures. Int. J. Fatigu. 2009, 31, 1598-1602. [CrossRef]

26. Wu, S.P.; Ye, Q.S.; Li, N. Investigation of rheological and fatigue properties of asphalt mixtures containing polyester fibers. Constr. Build. Mater. 2008, 22, 2111-2115. [CrossRef]

27. Tayfur, S.; Ozen, H.; Aksoy, A. Investigation of rutting performance of asphalt mixtures containing polymer modifiers. Constr. Build. Mater. 2007, 21, 328-337. [CrossRef]

28. Xiong, R.; Fang, J.H.; Xu, A.H.; Guan, B.W.; Liu, Z.Z. Laboratory investigation on the brucite fiber reinforced asphalt binder and asphalt concrete. Constr. Build. Mater. 2015, 83, 44-52. [CrossRef]

29. Imaninasab, R. Effect of granular polymers on rutting performance of SMA with respect to modification process. Constr. Build. Mater. 2017, 130, 64-72. [CrossRef]

30. Wang, Y.H.; Chong, D.; Wen, Y. Quality verification of polymer-modified asphalt binder used in hot-mix asphalt pavement construction. Constr. Build. Mater. 2017, 150, 157-166. [CrossRef]

31. Hajikarimi, P.; Tehrani, F.F.; Nejad, F.M.; Absi, J.; Rahi, M.; Khodaii, A.; Petit, C. Mechanical Behavior of Polymer-Modified Bituminous Mastics. I: Experimental Approach. J. Mater. Civ. Eng. 2019, 31, 04018337. [CrossRef]

32. Hajikarimi, P.; Tehrani, F.F.; Nejad, F.M.; Absi, J.; Khodaii, A.; Rahi, M.; Petit, C. Mechanical Behavior of Polymer-Modified Bituminous Mastics. II: Numerical Approach. J. Mater. Civ. Eng. 2019, 31, 04018338. [CrossRef] 
33. Cheng, Y.C.; Wang, W.S.; Gong, Y.F.; Wang, S.R.; Yang, S.T.; Sun, X. Comparative Study on the Damage Characteristics of Asphalt Mixtures Reinforced with an Eco-Friendly Basalt Fiber under Freeze-thaw Cycles. Materials 2018, 11, 2488. [CrossRef] [PubMed]

34. Wang, D.; Wang, L.B.; Gu, X.Y.; Zhou, G.Q. Effect of Basalt Fiber on the Asphalt Binder and Mastic at Low Temperature. J. Mater. Civ. Eng. 2013, 25, 355-364. [CrossRef]

35. Wang, D.; Wang, L.B.; Christian, D.; Zhou, G.Q. Fatigue Properties of Asphalt Materials at Low In-Service Temperatures. J. Mater. Civil. Eng. 2013, 25, 1220-1227. [CrossRef]

36. Gu, X.Y.; Xu, T.T.; Ni, F.J. Rheological behavior of basalt fiber reinforced asphalt mastic. J. Wuhan. Univ. Technol. 2014, 29, 950-955. [CrossRef]

37. Qin, X.; Shen, A.Q.; Guo, Y.C.; Li, Z.N.; Lv, Z.H. Characterization of asphalt mastics reinforced with basalt fibers. Constr. Build. Mater. 2018, 159, 508-516. [CrossRef]

38. Zhang, X.Y.; Gu, X.Y.; Lv, J.X.; Zhu, Z.K.; Ni, F.J. Mechanism and behavior of fiber-reinforced asphalt mastic at high temperature. Int. J. Pavement Eng. 2018, 19, 407-415. [CrossRef]

39. Zhang, X.Y.; Gu, X.Y.; Lv, J.X.; Zhu, Z.K.; Zou, X.Y. Numerical analysis of the rheological behaviors of basalt fiber reinforced asphalt mortar using ABAQUS. Constr. Build. Mater. 2017, 157, 392-401. [CrossRef]

40. Zhang, X.Y.; Gu, X.Y.; Lv, J.X. Effect of basalt fiber distribution on the flexural-tensile rheological performance of asphalt mortar. Constr. Build. Mater. 2018, 179, 307-314. [CrossRef]

41. Wang, W.S.; Cheng, Y.C.; Tan, G.J. Design Optimization of SBS-Modified Asphalt Mixture Reinforced with Eco-Friendly Basalt Fiber Based on Response Surface Methodology. Materials 2018, 11, 1311. [CrossRef]

42. Cui, P.D.; Xiao, Y.; Fang, M.J.; Chen, Z.W.; Yi, M.W.; Li, M.L. Residual Fatigue Properties of Asphalt Pavement after Long-Term Field Servic. Materials 2018, 11, 892. [CrossRef] [PubMed]

43. Wang, W.S.; Cheng, Y.C.; Tan, G.J.; Shi, C.L. Pavement Performance Evaluation of Asphalt Mixtures Containing Oil Shale Waste. Road. Mater. Pavement 2018, 1-22. [CrossRef]

44. Cheng, Y.C.; Wang, W.S.; Tan, G.J.; Shi, C.L. Assessing High- and Low-Temperature Properties of Asphalt Pavements Incorporating Waste Oil Shale as an Alternative Material in Jilin Province, China. Sustainability 2018, 10, 2179. [CrossRef]

45. JTG E20-2011. Standard Test Methods of Bitumen and Bituminous Mixtures for Highway Engineering; Ministry of Transport of the People's Republic of China: Beijing, China, 2011. (In Chinese)

46. Ma, T.; Ding, X.H.; Wang, H.; Zhang, W.G. Experimental Study of High-Performance Deicing Asphalt Mixture for Mechanical Performance and Anti-Icing Effectiveness. J. Mater. Civ. Eng. 2018, 30, 04018180. [CrossRef]

47. Ma, T.; Wang, H.; He, L.; Zhao, Y.L.; Huang, X.M.; Chen, J. Property Characterization of Asphalt Binders and Mixtures Modified by Different Crumb Rubbers. J. Mater. Civ. Eng. 2017, 29, 04017036. [CrossRef]

48. Guo, Q.L.; Li, L.L.; Cheng, Y.C.; Jiao, Y.B.; Xu, C. Laboratory evaluation on performance of diatomite and glass fiber compound modified asphalt mixture. Mater. Des. 2015, 66, 51-59. [CrossRef]

49. Zeng, B.; Luo, C.M.; Liu, S.F.; Bai, Y.; Li, C. Development of an optimization method for the GM(1,N) model. Eng. Appl. Artif. Intell. 2016, 55, 353-362. [CrossRef]

50. Ren, J.Z. GM(1,N) method for the prediction of anaerobic digestion system and sensitivity analysis of influential factors. Bioresour. Technol. 2018, 247, 1258-1261. [CrossRef]

51. Ren, J.Z.; Gao, S.Z.; Tan, S.Y.; Dong, L.C. Prediction of the yield of biohydrogen under scanty data conditions based on GM(1,N). Int. J. Hydrogen Energy 2013, 38, 13198-13203. [CrossRef]

(C) 2018 by the authors. Licensee MDPI, Basel, Switzerland. This article is an open access article distributed under the terms and conditions of the Creative Commons Attribution (CC BY) license (http://creativecommons.org/licenses/by/4.0/). 